\title{
Comparing Quality of Life of Elderly Menopause Living in Urban and Rural Areas
}

\author{
Mohammad Heidari ${ }^{1}$, Rahim Ali Sheikhi ${ }^{2}$, Parvin Rezaei ${ }^{3}$, Shokouh Kabirian Abyaneh ${ }^{4}$ \\ ${ }^{1}$ Community-Oriented Nursing Midwifery Research Center, Shahrekord University of Medical Sciences, ShahreKord, Iran, ${ }^{2}$ Health \\ Management and Economics Research Center, Iran University of Medical Sciences, Tehran, Iran, ${ }^{3}$ Department of Infectious Disease and \\ Tropical Medicine, Shariati Hospital, Tehran University of Medical Sciences, Tehran, Iran, ${ }^{4}$ Department of Nursing, Shahid Beheshti University \\ of Medical Sciences, Tehran, Iran
}

Objectives: The present study aimed to compare the quality of life of elderly menopause living in urban/rural areas of Abadeh, Iran.

Methods: This descriptive and cross-sectional study was conducted on 312 urban and 68 rural elderly population using the two-stage (systematic random classification) and objective-based sampling methods. Data were collected by Leiden-Padua questionnaire for assessment of quality of life in elderly menopause. SPSS software (version 21) and descriptive-analytical tests were used for data analysis.

Results: The results showed that the overall quality of life was 37.5 and 34.2 in rural and urban areas, respectively, and no statistically significant difference was observed between them. However, there was statistically significant difference in the mean score of depression and anxiety, cognitive function, social function, life satisfaction, and sexual activity in urban and rural elderly menopause $(P<0.001)$.

Conclusions: It seems necessary to pay more attention to the elderly menopause to improve their quality of life and consider proper planning for their empowerment and coping skills training. (J Menopausal Med 2019;25:28-34)

Key Words: Quality of life · Elderly · Menopause · Urban population · Rural population

\section{Introduction}

Aging is a natural process that is one of the stages of human growth and development. Improvement in living conditions, health care, longevity, and life expectancy has been associated with aging phenomenon in societies. ${ }^{1,2}$ The series of changes that occur by increasing the age, especially in the aging period, comprise the main issues of this transition period, including: death of the relatives along with loss of power, life goals, and physical skills. ${ }^{3}$ Since the ag- ing phenomenon affects all aspects of human life addressing its challenges and adopting appropriate policies to improve physical, social, and mental status of the elderly is crucial. ${ }^{1,3}$

Women are confronted with specific issues arising from their physiological conditions. One of these issues is the menopausal transition during which women experience additional problems due to the reduction in estrogen. ${ }^{4}$ Menopause is part of the critical phases of a woman's life, which characterizes the transition from fertility to infertility. ${ }^{5}$ Menopause is inevitable and goes back to the early history

Received: July 8, 2018 Revised: August 13, 2018 Accepted: September 24, 2018

Address for Correspondence: Rahim Ali Sheikhi, Health Management and Economics Research Center, Iran University of Medical Sciences, No 6, Rashid Yasemi St., Vali-e-asr Ave., Tehran, Iran

Tel: +98-913-2810140, Fax: +98-21-8888-3334, E-mail: rahim.shaykhi94@gmail.com

ORCID: https://orcid.org/0000-0002-2034-8624 
of human creation. Its occurrence in women has been associated with different cultural, economic, and religious attitudes. ${ }^{6,7}$ With aging in women and the occurrence of menopausal phenomena, changes in their various dimensions of health, will occur (physical, psychological and various types of diseases) therefore, with regard to these changes, the elderly menopause is vulnerable and decrease quality of life. ${ }^{8}$

Aging is a critical period of life, and considering the problems and needs of this stage is a social necessity. However, health promoting behaviors and quality of life are important issue that have been neglected. ${ }^{9}$ Latest resources introduce quality of life as degrees of satisfaction and achieving the needs in physical, social, psychological, structural, behavioral, and activity related domains, and more importantly the feeling of well-being. ${ }^{10,11}$ Quality of life assessment in clinical trials lead to closer ties between patients, physicians, and health care providers that consequently increases patients' awareness of their diseases, familiarize people with their health conditions and the advantages and disadvantages of different treatment, and emphasizes on the role of patients in choosing therapeutic approaches. ${ }^{12}$ Therefore, considering quality of life and the influence of psychology and lifestyle can increase the efficiency and independence of the elderly significantly, and help them to manage multiple complications and various treatments in the aging period. ${ }^{13}$ Quality of life is a subjective component of welfare, and in elderly means more emphasis on social policy, and reforming social goals in order to establish productive life for the elderly. ${ }^{14}$ Quality of life in elderly is largely dependent on the social environment in which they live. This issue is affected by physical, psychological and social changes in this period. Especially since the elderly menopause have been identified as a vulnerable population, and are one of the sections of society that comprise most of the healthcare services due to their chronic and acute diseases. ${ }^{15,16}$ Quality of life is often characterized by objective and subjective dimensions. The objective dimensions include standard of living, income, education, health, economic status, and social interaction. While the subjective dimensions comprise life satisfaction, happiness, and the value with which a person lives. ${ }^{17}$ Based on the statistics, the proportion of elderly population in rural areas are higher than urban areas than urban areas, especially due to the migration from rural to urban areas. In fact, many rural residents are in elderly age. This issue affects the quality of life in rural areas. ${ }^{18}$ It seems elders who live in rural areas are at the risk of reduced quality of life compared to those who live in urban areas, especially because of the economic and social factors. Therefore, considering the needs of the elderly with respect to their regional, cultural, social, and economic differences seems necessary, in order to provide appropriate planning for them. ${ }^{19}$ The present study aimed to compare the quality of life of elderly living in urban and rural areas of Abadeh city (Iran).

\section{Materials and Methods}

This descriptive, cross-sectional study was conducted to evaluate the quality of life of elderly menopause living in urban and rural areas of Abadeh city (Iran). The twostage (systematic random classification) and objective-based sampling methods were utilized in this study. By referring to health centers in 312 and 68 elderly menopause were selected in urban and rural areas, respectively, through systematic random sampling. It is necessary to mention that the sample size of 380 elderly menopauses was calculated according to the following formula:

$$
\mathrm{n}=\frac{\mathrm{Nz}^{2} \mathrm{pq}}{(\mathrm{N}-1) \mathrm{d}^{2}+\mathrm{z}^{2} \mathrm{pq}}
$$

where $\alpha=380, p=q=0.5, d=0.05, z=1.96, N=11,385$.

The researcher then referred to their homes and if the elderly menopause met the inclusion criteria and provided the consent to answer the questions, were included in the study.

The inclusion criteria were as follows: aged more than 60 years; living in urban or rural areas of Abadeh city at the time of data collection; and providing the consent to participate in the study. While those who were severely ill (need to be hospitalized), had hearing problems, were guests from other regions of the country, had foreign nationality and cognitive disorders were excluded from the study. In order to collect data, the researcher admitted to the homes of elderly menopause, and after getting informed about their characteristics, if they met the criteria for inclusion, gave them 
necessary information about the aims of the study and get their informed consent. After selecting the eligible participant, the researcher was introduced to them and the objectives of the study were elaborated for the participants. The informed consent was obtained from the subjects and they were assured that their information will remain confidential.

The questionnaires were then filled with the interview method. The information was collected using Leiden-Padua questionnaire (LEIPAD) for assessment of quality of life in elderly along with demographic information questionnaire. LEIPAD questionnaire was developed in 1998 by De Leo et al. $^{20}$ and can be easily used as an international tool in all seniors' groups in different communities. The questionnaire has 31 questions that evaluate the quality of life of the elderly menopause in seven dimensions of physical function, self-care, depression, anxiety, cognitive function, social function, sexual function and satisfaction with life. The questions in this questionnaire are scored with Likert scale and the responses are scored from zero (poor condition) to three (very good). The highest score in this questionnaire is 93. ${ }^{20}$ This questionnaire was translated and standardized in Iran by Sajadi and Biglarian, ${ }^{21}$ and its validity and reliability was confirmed $(\alpha=0.874)$. Preliminary data were analyzed by SPSS version 21 (IBM Corp., Armonk, NY, USA) software, along with descriptive indices (mean, standard deviation, frequency, etc.,) independent $t$ test, Scheffe test, and ANOVA.

\section{Results}

Based on the findings, of total 380 participants, 312 were from urban areas, while 68 participants were from rural areas and none of the samples were excluded from the research. In addition, 278 persons were married individuals, and 102 persons were widows and/or single. Other demographic information is provided in Table 1.

Among the demographic characteristics, there was a significant relationship between the quality of life of the elderly and the job status, disease status, and age $(P<0.05)$. there was no significant relationship with marital status, gender, residence, educational status, and family members $(P$ $>0.05)$.
Comparing the quality of life and its dimensions including physical activity, self-care, depression, anxiety, cognitive function, social function, life satisfaction, and sexual activity revealed that the overall average of quality of life in rural and urban areas were 37.5 and 34.2 , respectively, and the difference was not statistically significant. However, there was significant difference in the mean score of depression and anxiety, cognitive function, social function, life satisfaction, and sexual activity in urban and rural elderly menopause. The mean cognitive function was 40.84 in rural and 32.7 in urban elderly menopause.

The mean scores of depression and anxiety dimension were 42.27 and 34.63 in rural and urban areas, respectively,

Table 1. Demographic characteristics of the samples $(n=380)$

\begin{tabular}{|c|c|c|}
\hline \multicolumn{2}{|c|}{ Variable } & \multirow{2}{*}{$\begin{array}{c}\text { Frequency } \\
312(82.1)\end{array}$} \\
\hline Residence & Urban & \\
\hline & Rural & 68 (17.9) \\
\hline \multirow[t]{2}{*}{ Educational status } & Illiterate & $260(68.4)$ \\
\hline & Literate & $120(31.6)$ \\
\hline \multirow[t]{4}{*}{ Family members } & Spouse & $201(52.8)$ \\
\hline & Wife and children & 119 (31.3) \\
\hline & Children & 45 (11.9) \\
\hline & Alone & $15(3.9)$ \\
\hline \multirow[t]{3}{*}{ Job status* } & Retired and unemployed & $250(65.8)$ \\
\hline & Pensioner & $95(25.0)$ \\
\hline & Practitioner & $35(9.2)$ \\
\hline \multirow[t]{2}{*}{ Marital status } & Divorced and single & $102(26.8)$ \\
\hline & Married & $278(73.2)$ \\
\hline \multirow[t]{2}{*}{ Income } & Independent & 307 (80.8) \\
\hline & Dependent & 73 (19.2) \\
\hline \multirow[t]{6}{*}{ Disease* condition } & Blood pressure & $155(40.8)$ \\
\hline & Asthma & $17(4.5)$ \\
\hline & Heart disease & 48 (12.6) \\
\hline & Diabetes & $60(15.8)$ \\
\hline & Other diseases & $30(7.9)$ \\
\hline & Healthy & 70 (18.4) \\
\hline
\end{tabular}

The data is presented as number (\%). ${ }^{*} P<0.05$. 
while the respected values were 41.95 and 32.45 for social dimension in these groups. The mean scores in life satisfaction and sexual activity dimensions were 49.96 and 79.24 in rural areas, and 37.17 and 70.04 in urban areas, respectively. As it was noted, the difference between these values was statistically significant. The values in rural areas were higher than urban areas (Table 2).

As it is shown in Table 3, the score of quality of life in elderly menopause was highest in the attitude to sexual activity (71.51) and lowest in self-care (30.05). The results of Pearson correlation coefficient test, regarding the relationship between demographic characteristics and quality of life indicated that there is a statistically significant association between age and total score and domains of quality of life. In fact, as the age increases the quality of life decreases $(P<$ 0.001). While the results suggested that the only significant difference is between the total score of quality of life and the domains of depression and anxiety, cognitive function, social function, life satisfaction, sexual attitude, and the disease condition $(P<0.001)$.
The overall score of quality of life and its dimensions in various occupational groups shows a statistically significant difference $(P<0.001)$. However, this relationship was only observed in dimensions of cognitive function, social function, and sexual attitude. The findings demonstrated that sig-

Table 3. Mean and standard deviation of the quality of life of the elderly menopause

\begin{tabular}{lccc}
\hline \multicolumn{1}{c}{ Quality of life index } & Number & Mean & SD \\
\hline Physical activity & 379 & 34.44 & 22.71 \\
Self-care & 380 & 30.05 & 24.8 \\
Depression and anxiety & 380 & 36.1 & 22.45 \\
Cognitive activity & 380 & 33.75 & 22.75 \\
Social activity & 380 & 34.27 & 23.55 \\
Life satisfaction & 380 & 39.63 & 22.5 \\
Attitude to sexual activity & 344 & 71.51 & 27.71 \\
Overall quality of life & 343 & 34.73 & 19.52 \\
\hline
\end{tabular}

SD, standard deviation.

Table 2. Aspects of quality of life

\begin{tabular}{|c|c|c|c|c|c|}
\hline Quality of life index & Residence & Number & Mean & SD & $P$ value \\
\hline \multirow[t]{2}{*}{ Physical activity } & Urban & 306 & 33.62 & 23.57 & 0.096 \\
\hline & Rural & 73 & 37.88 & 18.40 & \\
\hline \multirow[t]{2}{*}{ Self-care } & Urban & 307 & 30.33 & 25.99 & 0.597 \\
\hline & Rural & 73 & 28.9 & 19.18 & \\
\hline \multirow[t]{2}{*}{ Depression and anxiety } & Urban & 307 & 34.63 & 22.66 & 0.009 \\
\hline & Rural & 73 & 42.27 & 20.56 & \\
\hline \multirow[t]{2}{*}{ Cognitive activity } & Urban & 307 & 32.07 & 23.19 & 0.001 \\
\hline & Rural & 73 & 40.84 & 19.40 & \\
\hline \multirow[t]{2}{*}{ Social activity } & Urban & 307 & 32.45 & 23.75 & 0.002 \\
\hline & Rural & 73 & 41.95 & 21.14 & \\
\hline \multirow[t]{2}{*}{ Life satisfaction } & Urban & 307 & 37.17 & 22.58 & 0.000 \\
\hline & Rural & 73 & 49.96 & 17.09 & \\
\hline \multirow[t]{2}{*}{ Attitude to sexual activity } & Urban & 289 & 70.04 & 28.06 & 0.024 \\
\hline & Rural & 55 & 79.24 & 24.63 & \\
\hline \multirow[t]{2}{*}{ Overall quality of life } & Urban & 288 & 34.2 & 20.41 & 0.041 \\
\hline & Rural & 55 & 37.5 & 13.85 & \\
\hline
\end{tabular}

$\mathrm{SD}$, standard deviation. 
nificant difference with companions in the home is only in domains of cognitive function, social function, life satisfaction, and sexual attitude $(P<0.001)$. But independent $t$ test revealed that there is a statistically significant difference in sexual attitude and marital status $(P<0.001)$.

\section{Discussion}

Comparing the quality of life and its dimensions including physical activity, self-care, depression, anxiety, cognitive function, social function, life satisfaction, and sexual activity revealed that the difference in overall average of quality of life in rural and urban areas was not statistically significant. While the mean score of depression and anxiety, cognitive function, social functioning, life satisfaction and sexual activity in urban and rural elderly menopause showed a statistically significant difference. It seems that the lack of significant difference in overall quality of life in urban and rural areas' residents is due to the proximity of the urban and rural districts in Abadeh city. Another study by Zhou ${ }^{22}$ in China indicated that by comparing quality of life in urban and rural areas, all aspects of quality of life, except public health, were lower in rural population than urban population.

In another study it was found that the difference between the quality of life in urban and rural areas is related to socioeconomic factors, lack of trust in health services, and lack of similar attitude to independence in villages that leads to growing dissatisfaction of quality of life in rural elderly menopause. ${ }^{23}$ In study Kelekçi et al. $^{24}$ found that vulvar dermatoses was particularly significantly associated with decreased quality of life. Another research on comparing urban and rural lifestyle in Chinese elderly population demonstrated that the quality of life in is lower in village than the city, and rural menopause have higher symptoms of depression due to solitude that consequently can lead to lower quality of life in these menopause. ${ }^{25}$ In terms of significant association between domains of social activity in both groups, Baernholdt et al. ${ }^{26}$ suggested that the domain of social activity is inferior in rural seniors compared to urban elderly.

The results of Pearson correlation coefficient regarding the relationship between age and quality of life indicated that there is a significant and inverse association between age and all aspects of quality of life along with overall score of quality of life. Similarly, Mohaqeqi Kamal et al. ${ }^{27}$ suggested that quality of life is significantly and inversely associated with age in elderly people. In evaluation of the relationship between marital status and quality of life the findings showed a significant relationship between marital status and sexual activity dimension. In fact the mean score of sexual activity among the married elderly (18.84) was higher than widow and single seniors (15.67). In line with previous research, Alipour et al. ${ }^{28}$ suggested that the average scores for overall quality of life is higher in married elderly people. They believed this is associated with more supporting networks in married people.

However, this association has not been confirmed in Mohaqeqi Kamal et al. ${ }^{27}$ and Khalesi ${ }^{29}$ studies. Regarding the association between gender and quality of life of the elderly, consistent with Ahmadi et al.'s study, ${ }^{30}$ the findings of the present study indicated that the overall quality of life score is not significantly associated with gender. In addition, quality of life in social relations' dimension was higher in women compared to men which corroborates Apidechkul ${ }^{31}$ findings. In terms of the association between level of education and quality of life in elderly menopause, in most domains (cognitive function and social activities) there was a statistically significant relationship. In fact, most elderly people with higher educational levels had higher average scores compared to those with lower levels of education. This finding match previous research that considered education as a crucial factor in dynamic elderly lifestyle. ${ }^{32}$

The results of this study showed that there the overall quality of life score and scores of physical activity, self-care, depression and anxiety, cognitive function, life satisfaction, and sexual activity dimensions had significant difference in various occupational groups. The Scheffe test indicated that in domains of physical activity, depression and anxiety, and cognitive function the scores of pensioners and working people has no significant difference, while the scores of retired people were higher than them. These findings are consistent with Rezvani et al.'s study. ${ }^{33}$ In the study of Shirvani and Heidari, ${ }^{6}$ the mean total score of quality of life of member of the association was significantly greater than 
non-members of the elderly support association.

Cross-sectional design of the study along with its dependency to the time and place of the interview and mood states of the elderly are amongst the limitations of this study. For further research, it is suggested that investigation be conducted in larger communities, and the comparison be performed on elderly people living in urban and rural areas and those living in nursing homes.

Despite the impact of various variables on quality of life of elderly menopause in urban and rural areas, by implementing specific plans to improve the quality of life of elderly, including social and economic support, and providing appropriate conditions for them to fulfill their emotional and psychological needs effective steps can be taken to enhance the quality of life of elderly menopause in urban and rural areas, and minimize the negative impacts of these variables on their lives.

\section{Acknowledgements}

The authors want to express a special recognition to the elderly menopause who have participated in the data collection of this study, without whom the study could not be possible.

\section{Conflict of Interest}

No potential conflict of interest relevant to this article was reported.

\section{References}

1. Heidari M, Shahbazi S. Effect of self-care training program on quality of life of elders. Iran J Nurs 2012; 25: 1-8.

2. Heidari M, Ghodusi M, Shirvani M. Loneliness in elderly and non-elderly residents of nursing homes. Int J Nurs Edu 2016; 8: 71-6.

3. Trentini CM, Chachamovich E, Wagner GP, Müller DH, Hirakata VN, de Almeida Fleck MP. Quality of Life (QoL) in a Brazilian sample of older adults: the role of sociodemographic variables and depression symptoms. Appl Res Qual
Life 2011; 6: 291-309

4. Heidari M, Ghodusi M, Rafiei H. Sexual self-concept and its relationship to depression, stress and anxiety in postmenopausal women. J Menopausal Med 2017; 23: 42-8.

5. Zivdir P, Sohbet R. Effect of feelings of guilt and shame on life quality of women in menopause. J Menopausal Med 2017; 23: 5-14.

6. Shirvani M, Heidari M. Quality of life in postmenopausal female members and non-members of the elderly support association. J Menopausal Med 2016; 22: 154-60.

7. Jafari M, Seifi B, Heidari M. Risk assessment: factors contributing to discomfort for menopausal women in workplace. J Menopausal Med 2017; 23: 85-90.

8. Donmez L, Gokkoca Z, Dedeoglu N. Disability and its effects on quality of life among older people living in Antalya city center, Turkey. Arch Gerontol Geriatr 2005; 40: 213-23.

9. Netuveli G, Blane D. Quality of life in older ages. Br Med Bull 2008; 85: 113-26.

10. Heidari M, Ghodusi M. Relationship of assess self-esteem and locus of control with quality of life during treatment stages in patients referring to drug addiction rehabilitation centers. Mater Sociomed 2016; 28: 263-7.

11. Shobeiri F, Jenabi E, Hazavehei SM, Roshanaei G. Quality of life in postmenopausal women in Iran: a populationbased study. J Menopausal Med 2016; 22: 31-8.

12. King A, Proutt A, Phillips A. Comparative effects of two physical functioning and quality of life out comes in older adults. J Gerontol Med Sci 2006; 137: 825-32.

13. Jadidi A, Farahaninia M, Janmohammadi S, Haghani H. The relationship between spiritual well-being and quality of life among elderly people residing in Kahrizak senior house. Iran J Nurs 2011; 24: 48-56.

14. Hoi le V, Chuc NT, Lindholm L. Health-related quality of life, and its determinants, among older people in rural Vietnam. BMC Public Health 2010; 10: 549.

15. Hoi le V, Thang P, Lindholm L. Elderly care in daily living in rural Vietnam: need and its socioeconomic determinants. BMC Geriatr 2011; 11: 81.

16. Heidari M, Ghodusi Borujeni M, Naseh L. Comparison of self-efficacy and loneliness between community-dwelling \& institutionalized older people. Iran J Ageing 2016; 11: 14251.

17. Sengul Y, Kara B, Arda MN. The relationship between health locus of control and quality of life in patients with chronic low back pain. Turk Neurosurg 2010; 20: 180-5.

18. Canbaz S, Sünter AT, Dabak S, Pekşen Y. The prevalence of chronic diseases and quality of life in elderly people in Samsun. Turk J Med Sci 2003; 33: 335-40.

19. Fotoukian Z, Mohammadi Shahboulaghi F, Fallahi Khosh- 
knab M. Analytical on empowerment interventions in older people with chronic disease: a review literature. J Health Promot Manag 2013; 2: 65-76.

20. De Leo D, Diekstra RF, Lonnqvist J, Trabucchi M, Cleiren $\mathrm{MH}$, Frisoni GB, et al. LEIPAD, an internationally applicable instrument to assess quality of life in the elderly. Behav Med 1998; 24: 17-27.

21. Sajadi H, Biglarian A. Quality of life among elderly women in Kahrizak Charity Foundation, Tehran, Iran. Payesh 2007; 6: 105-8.

22. Zhou B, Chen K, Wang J, Wang H, Zhang S, Zheng W. Quality of life and related factors in the older rural and urban Chinese populations in Zhejiang province. J Appl Gerontol 2011; 30: 199-225.

23. Cleary KK, Howell DM. Using the SF-36 to determine perceived health-related quality of life in rural Idaho seniors. J Allied Health 2006; 35: 156-61.

24. Kelekçi KH, Özyurt S, Özkan B, Karaca Ş, Karakuzu A, Bilgin I. The impact of inflammatory and infectious diseases of vulvar on quality of life. J Menopausal Med 2016; 22: 1318.

25. Dong X, Simon MA. Health and aging in a Chinese population: urban and rural disparities. Geriatr Gerontol Int 2010; 10: 85-93.

26. Baernholdt M, Yan G, Hinton I, Rose K, Mattos M. Quality of life in rural and urban adults 65 years and older: find- ings from the National Health and Nutrition Examination survey. J Rural Health 2012; 28: 339-47.

27. Mohaqeqi Kamal H, Sajadi H, Zare H, Beiglarian A. Elderly quality of life: a comparison between pensioners of Social Security Organization and National Retirement Fund (Qom County, 2006). J Health Adm 2007; 10: $49-56$.

28. Alipour F, Sajadi H, Forouzan A, Nabavi H, Khedmati E. The role of social support in the anxiety and depression of elderly. Iran J Ageing 2009; 4: 53-61.

29. Khalesi M. Comparison of quality of life, educated and uneducated women employed in Qom [Msc thesis]. Tehran: University of Welfare and Rehabilitation Sciences; 2009.

30. Ahmadi F, Salar A, Faghihzadeh S. Quality of life in Zahedan elderly population. J Fac Nurs Midwifery 2004; 10: 617.

31. Apidechkul T. Comparison of quality of life and mental health among elderly people in rural and suburban areas, Thailand. Southeast Asian J Trop Med Public Health 2011; 42: 1282-92.

32. Albokorki M, Ramezani M, Arizi F. Quality of life in the elderly of Shahinshahr, 2004. Jundishapur Sci Med J 2006; 5: 703-9.

33. Rezvani MR, Mansourian H, Ahmadadadi H, Ahmadadadi F, Here-Dasht SP. An assessment on factors affecting the quality of life of elderly in rural regions (case study: Neishabour county). J Rural Res 2013; 4: 301-26. 